\title{
Abordagens ao ensino: implicações no processo de aprendizagem dos alunos
}

\section{Approaches to teaching: implications in the process of the students learning}

\section{Enfoques de enseñanza: implicaciones en el proceso de aprendizaje de los estudiantes}

\author{
Maria Olímpia Almeida de Paiva* \\ Centro de Investigação em Psicologia e Educação do AEAH - CIPE, Porto, Portugal
}

\author{
Abílio Afonso Lourenço** \\ Centro de Investigação em Psicologia e Educação do AEAH - CIPE, Porto, Portugal
}

\begin{abstract}
RESUMO
$\mathrm{Na}$ perspetiva da investigação SAL (Student Approaches to Learning) a abordagem ao ensino dos professores (transmissiva e compreensiva) influencia a abordagem à aprendizagem dos alunos. O objetivo deste texto é estimular os professores a refletirem sobre as suas práticas docentes e sobre a maneira como fomentam o sucesso educativo dos seus alunos no nível exigido. A partir da reflexão metacognitiva, os docentes poderão constatar a existência de diversos fatores que poderão ser reforçados e outros esquecidos, de modo a melhorar a qualidade da aprendizagem dos alunos. É, também, referida a importância de conhecer as conceções dos alunos acerca da forma como aprendem, com o objetivo de desenvolver contextos de ensino e aprendizagem que os alunos vivenciem como motores de abordagens à aprendizagem profundas. Isto implica necessariamente a opção por uma abordagem ao ensino centrada no aluno. Espera-se que este texto reflexivo possa contribuir para uma melhor compreensão das abordagens ao ensino, a fim de promover nos alunos comportamentos mais ajustados para a mestria escolar. São referidas algumas implicações educativas, assim como possíveis investigações futuras.
\end{abstract}

Palavras-chave: abordagens ao ensino, estratégias de ensino, sucesso escolar.

\begin{abstract}
In the SAL (Student Approaches to Learning) research view teachers' transmissive and comprehensive approach to teaching has a direct influence in the students' approach to learning. The purpose of this literature review is to urge teachers think about both their teaching methods and the way they nourish their students' learning at the required stage. The purpose of this meta-cognitive reflection is to make teachers able to recognize the many factors which need to be enhanced to get her with the ones which will have to be overlooked so that their students' learning can be improved. It also referred to the importance of knowing the conceptions of students about
\end{abstract}


their learning situation, in order to develop teaching and learning contexts students to experience as deep approaches to learning engines. This necessarily implies the choice of an approach to teaching student-centered. This text aims at making an enhanced contribution towards a better understanding of teaching approaches and at the same time promoting a more suitable and adjusted studying and learning behavior which has to be the most suitable one to meet the students' purposes. Are also indicated some educational implications as well as possible future research.

Keywords: approaches to learning, teaching strategies, school success.

\section{RESUMEN}

En la perspectiva de la investigación SAL (Student Approaches to Learning) el enfoque a la enseñanza de los profesores (transmisora y comprensiva) influye en el abordaje del aprendizaje de los estudiantes. El objetivo de este artículo es ayudar a los profesores a reflexionar sobre sus prácticas de enseñanza y sobre la forma de promover el aprendizaje del estudiante en el nivel requerido. A partir de la reflexión meta-cognitiva, los profesores pueden comprobar que hay muchos factores que pueden reforzarse y otros olvidados, con el fin de aumentar la calidad del aprendizaje de los estudiantes. Fue referida también la importancia de conocer la concepción de los estudiantes acerca de su situación de aprendizaje, con el fin de desarrollar contextos de enseñanza y aprendizaje que los estudiantes entiendan como motores de enfoques a los aprendizajes profundos. Se espera que este texto de reflexión pueda contribuir a una mejor comprensión de los enfoques para la enseñanza, para fomentar en los estudiantes conductas de aprendizaje y de estudio que mejor se adapten a sus metas y estilos de aprendizaje. Son referidas algunas implicaciones educativas, así que potenciales futuras investigaciones.

Palabras clave: enfoques de enseñanza, estrategias de enseñanza, éxito escolar.

\section{I ntrodução}

O ensino de qualidade não consiste na utilização de modelos e técnicas infalíveis de ensino, na medida em que cada situação de ensino e aprendizagem é singular e irrepetível.

(Prosser \& Trigwell, 2000)

Desde os primórdios da Psicologia da Educação sempre foi visível o cuidado em encontrar os fatores de influência no entendimento dos diversos processos de aprendizagem do aluno. I gualmente, e por motivos semelhantes, houve a sensibilidade de se procurar indagar acerca das abordagens ao ensino utilizadas na prática pedagógica dos professores em sala de aula, conforme é possível inferir a partir da investigação de Prosser, Trigwell e Taylor (1994). Frequentemente, aprendemos ao longo da vida sem nos preocuparmos com a natureza desse processo nem com a busca de um suporte teórico que explique o processo de ensino e de aprendizagem (Vasconcelos, Praia\& Almeida, 2003). 
A revisão da literatura PSI é unânime ao considerar que as abordagens adotadas pelos professores, nas respetivas práticas educativas, influenciam linearmente as opções das abordagens utilizadas nas aprendizagens dos alunos. Esta constatação é ainda mais evidente quando nos debruçamos especificamente no racional teórico SAL (Student Approaches to Learning) (Biggs, 1987; Chaleta, 2002; Duarte, 2002, 2004; Grácio, 2002; Kember, 2000; Kember, Biggs \& Leung, 2004; Marton \& Säljö, 1976; Prosser \& Trigwell, 2000; Rosário, Almeida, Núñez \& González-Pienda, 2004; Rosário, Ferreira \& Cunha, 2003; Rosário, Ferreira \& Guimarães, 2001; Rosário et al., 2005; Trigwell \& Prosser, 2004).

A linha de investigação SAL pode ser encarada como uma tentativa de fortalecer o papel dinâmico do aluno no seu processo de aprendizagem, aumentando a sua compreensão do sentido do mundo que nos circunda e desenvolvendo uma abordagem profunda ao real (Tsai, Tsai \& Hwang, 2015).

Os vastos estudos realizados nas últimas décadas, contemplando distintas culturas educativas, mostraram que este racional teórico, relativamente às abordagens ao ensino e, concomitantemente, às abordagens à aprendizagem, é uma linha de investigação credível, bem estruturada e que tem revelado resultados coincidentes na grande maioria dos estudos realizados (Lourenço \& Nogueira, 2014; Lourenço \& Paiva, 2010a; Paiva, 2007; Rosário, et al., 2010; Rosário et al., 2013).

Este racional teórico mostra-nos a importância de estimular os professores a refletirem acerca das suas práticas docentes e sobre a maneira como fomentam a aprendizagem dos alunos no nível exigido. A partir da reflexão metacognitiva, pondo em questão as suas práticas e desafios, os docentes poderão constatar, muito embora não haja, reconhecidamente, um método de ensino ideal, a existência de muitos fatores que poderão ser reforçados e outros esquecidos, de modo a aumentar a qualidade da aprendizagem dos alunos (Biggs \& Moore, 1993). Os mesmos autores referem que, se os professores pretendem estimular os seus alunos para a prática metacognitiva da sua aprendizagem, devem, acima de tudo, praticar a metacognição no seu ensino. O meta-ensino encaminha os professores a refletir sobre como e o que ensinar, tendo em consideração que cada uma das suas atitudes revela dois aspetos a serem tidos em conta: um lado funcional - o que é evidente para si próprio; e um lado de impacto - o que é evidente para os seus alunos. Rosário (1999) dános alguns exemplos de métodos que fomentam distintas abordagens às atividades acadêmicas dos alunos e à aprendizagem em geral, tais como o tipo de testes de avaliação, o valor que lhes é aplicado na avaliação final, tipo e frequência dos trabalhos de casa, tipos de aulas lecionadas, entre outros. Estes assuntos serão diluídos ao longo desta explanação. 
Assim, ancorado na teoria SAL, este artigo tem como objetivo estimular os professores a pensarem nas suas práticas docentes e na maneira como fomentam o sucesso educativo dos seus alunos no nível exigido. Pretende-se, também, apresentar a contribuição de uma reflexão, dando ênfase às abordagens de ensino dos professores e procurar associá-las às abordagens à aprendizagem dos alunos, descrevendo o predomínio de algumas delas nas perspectivas de ensino que foram sendo assumidas de uma forma progressiva.

\section{Abordagem ao ensino, uma aproximação ao conceito}

Grande parte das pesquisas acerca do ensino referidas na literatura PSI manifesta, como finalidade principal, encontrar maneiras de aperfeiçoamento, isto é, formas de aumentar os resultados acadêmicos dos alunos, focando, essencialmente, a análise das estratégias e dos métodos usados pelos docentes na sua prática letiva (Biggs \& Tang, 2011). Quando se quer uma alteração na prática dos professores, é evidente o papel desempenhado pelas intenções inerentes às estratégias de ensino. Nesta perspectiva, Trigwell, Prosser e Taylor (1994) referem que, para incrementar a qualidade do ensino, é imprescindível combinar as intenções às estratégias. Além do mais, as pesquisas que evidenciam como meta descrever a realidade do processo de ensino e de aprendizagem têm sido efetuadas através do ponto de vista do observador ou investigador, focando-se, principalmente, na avaliação das estratégias usadas pelos professores. Tendo como suporte as investigações relativas à aprendizagem e o modelo sugerido por Biggs (Biggs \& Moore, 1993), a identificação das intenções inerentes às estratégias de ensino deve ser um fim a seguir se desejarmos aperfeiçoar a qualidade do ensino (Trigwell \& Prosser, 1996).

O Modelo 3P (presságio - processo - produto) de Biggs, um quadro teórico fundamental na aprendizagem do aluno, fornece uma ferramenta poderosa para a compreensão das relações entre as percepções dos alunos sobre o ambiente de ensino e aprendizagem, estratégias de aprendizagem e resultados acadêmicos (Rosário et al., 2013). Um estudo de Ginns, Martin e Papworth (2014) sobre as relações entre variáveis de presságio, de processo e de produto, com uma amostra de 5198 alunos, em contexto de ensino secundário australiano, revelou que as variáveis presságio, percepção da autoeficácia acadêmica e o entendimento que o aluno tem sobre o apoio dado pelo professor têm uma influência forte e direta sobre variáveis de resultado, bem como efeitos fortes e indiretos através das variáveis de produto. As variáveis demográficas (idade, sexo, escolaridade dos pais) e de personalidade (Big Five) apresentaram menor importância. Este estudo ilustrou a utilidade e atualidade do 
modelo 3P neste contexto de ensino, para que quando o aluno melhora a sua percepção da autoeficácia, bem como do apoio dado pelo professor, melhores serão os processos e os produtos da aprendizagem.

Da análise do processo de ensino emergiram, assim, entre outras, as seguintes questões: será exequível identificar abordagens ao ensino qualitativamente distintas? As concepções que os professores apresentam sobre o ensino influenciarão as suas abordagens ao ensino? Será que as abordagens ao ensino apresentam algum impacto nas abordagens à aprendizagem adotadas pelos alunos? (Kember \& Kwan, 2000)

Prosser e Trigwell, desde a década de 1990 (Prosser \& Trigwell, 1997, 1998, 2000; Trigwell \& Prosser, 2004), têm conduzido investigação com a finalidade de encontrar soluções para as questões anteriormente formuladas. Esses investigadores efetuaram um estudo na linha fenomenográfica, compreendendo vinte e quatro professores, das licenciaturas de Ciências do ensino universitário, que foram sujeitos a uma entrevista sobre as suas experiências de ensino numa das suas turmas do primeiro ano (Prosser \& Trigwell, 1997, 2000). É de realçar que, numa perspectiva fenomenográfica, as abordagens ao ensino e à aprendizagem encerram uma natureza relacional. O mesmo será dizer que a abordagem escolhida por um professor está dependente da sua relação com um contexto particular de ensino e de aprendizagem. Esta linha de investigação, centrada nas abordagens ao ensino, replica nos professores a investigação desenvolvida por Marton (Marton \& Säljö, 1997) sobre a aprendizagem dos alunos, a qual caracteriza a abordagem à aprendizagem como a intenção e a estratégia que um aluno pratica quando aborda uma atividade ou uma determinada matéria de aprendizagem.

As entrevistas foram reproduzidas e o seu conteúdo analisado, com o fim de identificar as abordagens ao ensino dos professores em questão e as suas concepções de ensino e aprendizagem. As explanações dos professores foram, também, examinadas de acordo com as estratégias e as intenções a si associadas. O resultado final indicou quatro tipos de intenções (transmissão de informação, aquisição de conceitos, desenvolvimento conceptual e mudança conceptual) e três de estratégias (centrada no professor, focada na interação professor/aluno e centrada no aluno) que associadas deram origem a cinco abordagens ao ensino qualitativamente distintas ( $A, B$, C, D e E) (Trigwell \& Prosser, 2004). Verificou-se, assim, que da mesma forma que nas abordagens dos alunos à aprendizagem, as abordagens dos professores ao ensino são formadas por uma dimensão intencional e outra estratégica (Prosser \& Trigwell, 2000, 2006). As abordagens ao ensino assinaladas neste estudo, bem como 
os seus elementos intencionais e estratégicos, estão apresentados na tabela 1.

Tabela 1.

Componentes intenção e estratégia das cinco abordagens ao ensino (A-E) (Trigwell \& Prosser, 2004)

\begin{tabular}{|c|c|c|c|}
\hline \multirow[t]{2}{*}{ Intenção } & \multicolumn{3}{|l|}{ Estratégia } \\
\hline & $\begin{array}{l}\text { Focada no } \\
\text { professor }\end{array}$ & $\begin{array}{l}\text { Focada na } \\
\text { interação } \\
\text { professor/aluno }\end{array}$ & $\begin{array}{l}\text { Focada } \\
\text { no aluno }\end{array}$ \\
\hline $\begin{array}{l}\text { Transmissão } \\
\text { informação }\end{array}$ & A & & \\
\hline Aquisição de conceitos & B & $\mathrm{C}$ & \\
\hline $\begin{array}{l}\text { Desenvolvimento } \\
\text { conceptual }\end{array}$ & & & $\mathrm{D}$ \\
\hline Mudança conceptual & & & $\mathrm{E}$ \\
\hline
\end{tabular}

Dos vinte e quatro professores participantes, treze foram categorizados como tendo escolhido a abordagem $A$, seis a abordagem $B$, três a abordagem $C$, e somente um como tendo escolhido cada uma das abordagens D e E (Prosser et al., 1994). A maioria dos professores adotou abordagens exteriorizando a intenção de transferir aos alunos informação ou conceitos, usando, principalmente, estratégias centradas no professor. Em compensação, uma minoria adotou abordagens com a intenção de auxiliar os alunos a desenvolver ou a modificar a sua compreensão das ideias fundamentais, utilizando estratégias focadas nos alunos. As abordagens identificadas por estes investigadores foram relatadas como possuindo as características que se seguem, nomeadamente:

Abordagem A: Estratégia de ensino focada no professor com a intenção de transmitir conteúdos aos alunos - os professores que manifestam esta abordagem optam por uma estratégia de ensino focada neles próprios, com a intenção de transmitir informações acerca da disciplina que lecionam. O professor que opta por esta abordagem ao ensino tem como principal preocupação dar aos seus alunos muitos apontamentos para que alcancem bons resultados nos testes de avaliação (Martin et al., 2000; Trigwell, Prosser \& Waterhouse, 1999).

Abordagem B: Estratégia de ensino focada no professor com a intenção de fazer com que os alunos adquiram os conceitos da disciplina - os professores que exibem esta abordagem utilizam uma estratégia focada neles próprios, tal como na abordagem A. Estes professores creem que os seus alunos podem aprender conceitos e as suas relações se estes forem transmitidos claramente na aula, não concedendo, todavia, um papel dinâmico aos alunos no processo de 
ensino e de aprendizagem (Martin, et al., 2000; Prosser et al., 1994; Trigwell, et al., 1999).

Abordagem C: Estratégia de interação professor/aluno com a intenção de fazer com que os alunos adquiram os conceitos da disciplina - nesta abordagem, os docentes adotam uma estratégia centrada na interação professor/aluno com a finalidade de auxiliar os alunos a adquirirem os conceitos fundamentais da disciplina, bem como a relação entre estes conceitos. Os professores esforçam-se por explicar os conteúdos a aprender, tendo como principal objetivo transferir a informação, de uma forma exata, aos alunos (Martin et al., 2000; Prosser et al., 1994; Trigwell et al., 1999).

Abordagem D: Estratégia de ensino focada nos alunos com a intenção de fazer com que estes construam os conceitos por si próprios - os professores que escolhem esta abordagem dão ênfase às estratégias focadas nos alunos com a intenção de os ajudar a incrementar e alargar as concepções prévias e a visão do mundo. Estes docentes expressam a intenção de ensinar os alunos a aprenderem os conteúdos da disciplina, através do uso de exemplos relacionados com as suas vivências do quotidiano, a partir da demonstração dos princípios que devem ser aprendidos (Martin et al., 2000; Prosser et al., 1994; Trigwell et al., 1999).

Abordagem E: Estratégia de ensino focada nos alunos com a intenção de fazer com que estes mudem os seus próprios conceitos - nesta abordagem, os professores usam uma estratégia centrada nos alunos com a intenção de os ajudar a mudar as suas maneiras de ver o mundo ou as suas concepções acerca do fenómeno que estão estudando. Os docentes que optam por esta abordagem frente ao seu ensino, entendem que não podem transferir a sua visão do mundo para os alunos. Estes é que têm de a construir, reorganizando os seus próprios conhecimentos e, desta forma, a sua visão da realidade (Martin et al., 2000; Prosser et al., 1994; Trigwell et al., 1999).

Sheppard e Gilbert (1991) concretizaram estudos em que tentaram encontrar uma relação entre os métodos de ensino e a aprendizagem dos alunos, onde comprovaram que os docentes que na sua prática letiva manifestam abordagens semelhantes à $\mathrm{D}$ e $\mathrm{E}$ promovem a adoção, por parte dos alunos, de abordagens profundas.

Como nos é referido pela literatura (Lourenço \& Nogueira, 2014; Paiva 2007; Rosário et al., 2010), no que respeita à abordagem profunda, o aluno realiza a tarefa de aprendizagem com o intuito de obter um significado pessoal do texto. Inicia um processo dinâmico de aprendizagem no qual desafia os pensamentos, os argumentos e as certezas expostas pelo autor, onde tenta estabelecer pontos de ligação entre os pensamentos do texto e entre estes e a sua experiência pessoal. Este mecanismo exige que o indivíduo faça uma reorganização do conhecimento, construindo, por sua vez, uma estrutura própria. 
Prosser e colaboradores (1994) salientam que o ensino centrado no aluno promovia o aproveitamento escolar na medida em que tinha em conta a apresentação e a elaboração de concepções alternativas de conhecimento e era apoiado na discussão. Os mesmos autores recordam, ainda, que "os resultados obtidos no estudo descrito aludem para que os cursos que incluem um tipo de ensino que é direcionado às concepções que os alunos já possuem, têm mais probabilidade de fomentar a aprendizagem baseada numa orientação de significado pessoal e, em consequência, uma qualidade acrescida dos resultados da sua aprendizagem" (p. 82).

As cinco abordagens ao ensino identificadas por Prosser e Trigwell foram, então, separadas em dois conjuntos diferentes: (i) Abordagens A, B e C, centradas no professor ou na interação entre o professor e o aluno, retratando um ensino cuja intenção resume-se à transmissão de conhecimentos; e (ii) Abordagens D e E, centradas no aluno e caracterizando um ensino cuja intenção consta em facilitar os alunos a desenvolverem o seu próprio conhecimento. Cada um dos conjuntos revela a sua própria estrutura interna, não tendo sido reconhecidas intenções ou estratégias presentes nos dois conjuntos ao mesmo tempo: as abordagens $A$ e $B$ têm em comum uma estratégia, as abordagens B e C uma intenção e as abordagens D e E também uma estratégia. Não foram, deste modo, identificadas abordagens intermédias, como por exemplo, abordagens com intenções de incrementar os conceitos dos alunos mas operacionalizadas com estratégias centradas no professor (Trigwell \& Prosser, 1996).

Como se pode observar no estudo descrito, as abordagens ao ensino apresentam comunalidades com as abordagens dos alunos à aprendizagem, designadamente os elementos intencional e estratégico. Assim, apesar de não ser indicada a presença de uma relação causal entre si, as abordagens ao ensino A e $B$ parecem revelar características comuns com a abordagem superficial à aprendizagem.

Como refere Paiva (2007), na abordagem superficial não ocorre um envolvimento pessoal no ato de aprender, pois este é percebido como uma obrigação extrínseca. O aluno focaliza-se simplesmente no texto propriamente dito, preocupando-se, especialmente, com a memorização de um maior número de acontecimentos, fatos e ideias apresentadas, sem se preocupar em estabelecer relações entre si. Alude a um mecanismo automático de memorização, no qual o aluno raramente diferenciará o fundamental do acessório.

As abordagens ao ensino D e E parecem, por sua vez, manifestar características comuns com a abordagem profunda à aprendizagem. Em face destes resultados, emerge a questão: os docentes que optam pelas abordagens ao ensino A e B, desenvolvendo abordagens muito centradas na transmissão de conhecimentos, promoverão, nas 
suas salas de aula, abordagens superficiais à aprendizagem? (Prosser et al., 1994; Trigwell \& Prosser, 1996). Com vista a encontrar resposta a esta questão, estes investigadores deram início a um projeto que invocou metodologias de natureza quantitativa, na medida em que se tornava irrealizável, na perspectiva pragmática e econômica, o prosseguimento deste estudo com métodos qualitativos (Trigwell \& Prosser, 1996).

Através dos dados alcançados nas investigações de caráter qualitativo, Trigwell e Prosser (1996) construíram um questionário o ATI (Approaches to Teaching Inventory), com o objetivo de medir as intenções e as estratégias identificadas nos estudos fenomenográficos. O ATI revelou-se uma escala suficientemente forte e razoável, separando os professores que, na pesquisa qualitativa, se encontravam nos extremos da intenção e da estratégia. Este inventário foi desenvolvido a partir de um estudo relacional, pelo que os dados conseguidos não são forçosamente transpostos para outros contextos. Os autores referem, deste modo, a necessidade de ser testado de forma mais cuidada para se autenticar a sua validade em outros contextos (Prosser \& Trigwell, 2006; Trigwell \& Prosser, 1996). Em síntese, os resultados das investigações desenvolvidas por Prosser e Trigwell (Prosser \& Trigwell, 1997, 2000; Trigwell \& Prosser, 1996, 2004) e por Kember e colaboradores (Kember \& Kwan, 2000) deixam transparecer a existência de duas orientações ou abordagens ao ensino, com características idênticas.

\section{Abordagens ao ensino vs abordagens à aprendizagem - implicações educativas}

Tendo em consideração, novamente, as questões iniciais deste trabalho, e conjugando as contribuições do construto estudado (abordagens ao ensino) e do modelo teórico SAL associado, importa, agora, refletir sobre as diferentes contribuições da revisão da literatura efetuada para a prática educativa.

Nesta sequência, Entwistle e Ramsden (1983) constataram que uma avaliação geral positiva do contexto estava relacionada com o uso de uma abordagem profunda à aprendizagem. No mesmo propósito, uma investigação de Ramsden e Entwistle (1981) referiu que em departamentos percebidos pelos alunos como favorecendo um ensino de maior qualidade pedagógica se observavam resultados superiores na orientação para o significado (abordagem profunda). No entender de Richardson (2000), a investigação tenta certificar que as abordagens à aprendizagem estão dependentes da motivação intrínseca frente ao material a aprender e do modo de avaliação que se espera. O mesmo autor refere, ainda, que instigar os alunos a esperar uma avaliação focada nas propriedades superficiais do 
material relativo à aprendizagem parece incutir uma abordagem superficial. Os docentes devem, portanto, fazer um esforço para estimular os seus alunos a escolherem abordagens à aprendizagem de elevada complexidade estrutural.

É de destacar, todavia, que existem limites para essa influência, na medida em que muitos alunos adotam uma abordagem superficial apesar de vivenciarem um ensino de qualidade. Em consequência, a responsabilidade da opção por certa abordagem à aprendizagem não pode ser atribuída apenas ao ambiente educativo embora, dada a natureza responsiva das abordagens à aprendizagem, a forma como os alunos percebem o processo de avaliação, e em geral o ambiente de aprendizagem, deve ser tida em consideração pelos diferentes agentes educativos. Este aspecto sugere a necessidade de trabalhar e equipar os alunos para poderem autorregular as suas atividades de aprendizagem (Rosário, 2004). Por outro lado, quando um aluno é exposto a um ensino pouco instrutivo, ou seja, pouco centrado no aluno e mais centrado na transmissão dos conteúdos, é menos plausível que adote e mantenha uma abordagem profunda (Biggs, 2003).

Um ambiente educativo afável e cognitivamente estimulante, onde os erros podem ser criticados construtivamente, possui as condições para incentivar os alunos e fomentar o desenvolvimento de abordagens profundas (Biggs, 1996; Entwistle, Kozéki \& Tait, 1989). Por todos estes indicadores e exemplos, é fácil concluir a dificuldade de promover a escolha de uma abordagem profunda (Biggs, 2003; Marton \& Säljö, 1997; Ramsden, 1997), porém, determinados investigadores tentaram encontrar maneiras de incitar a adoção de uma abordagem profunda e, em consequência, beneficiar a aprendizagem. Marton (1988) apresenta três maneiras distintas de a operacionalizar. Depois de definirem e informarem qual o tipo de abordagem que elegem como mais adequada, os professores podem estabelecer um sistema educacional que Ihes facilite a concretização desses objetivos. O modelo de ensino e de aprendizagem que 0 professor arquiteta e o tipo de aprendizagem que defende podem ser concordantes com o modo de aprender de um grupo de alunos, contudo, outros podem ter muitos impedimentos para se adaptar ao tipo de aprendizagem preconizado pelo docente.

Deste modo, é fundamental determinar meios instrutivos a partir dos quais os alunos possam construir um rumo que lhes facilite atingir as suas expectativas. Uma das formas de o conseguir consiste em propor aos alunos conflitos cognitivos que os levem a repensar e a ponderar a sua forma usual de enfrentar um determinado fenómeno. Ter consciência de que há diversas maneiras de refletir e de abordar uma atividade de aprendizagem pode ser uma forma muito válida, não só de incrementar o entendimento numa tarefa de aprendizagem particular mas, igualmente, de aprender a aprender (Marton, 1988). 
Tobin (1987) refere que quando o tempo de espera entre as perguntas do professor e a resposta do aluno é aumentado, os alunos podem meditar sobre as suas respostas e, mesmo, elaborar novas questões. Se, como salienta Bruner (1971), a presença do professor na sala de aula permite errar sem penalizações, então a qualidade do discurso cognitivo dos alunos é incrementada, bem como os seus resultados acadêmicos. Aprender é um tipo de interação com o mundo. Durante a aprendizagem, as nossas concepções acerca dos fenómenos variam, uma vez que encaramos o mundo de outra maneira. Mas, não é a informação propriamente dita a causa de tal mudança, mas sim a maneira como organizamos essa informação e a refletimos.

Nesta sequência, como refere Biggs (2001, 2003), a educação é uma modificação conceptual e não somente um incremento de conhecimento. Esta modificação de conceitos é mais fácil que ocorra quando: (i) se gera uma situação de aprendizagem onde os alunos e professores conheçam nitidamente quais são os objetivos que são previstos para os alunos alcançarem; (ii) os alunos vivenciam a importância de atingir tais objetivos e onde a motivação é, assim, um resultado de um trabalho de cumplicidade com o material de aprendizagem e não o seu pré-requisito (Rosário, 2005); (iii) os alunos se centram na tarefa e não em inquietações colaterais, como as classificações escolares; e (iv) o benéfico diálogo entre os alunos e - professor leva a atividades que elaboram, aperfeiçoam e aprofundam a compreensão. Estes pontos revelam influências importantes para o desenho do ensino e para uma reflexão pessoal do professor sobre a sua prática pedagógica e sobre os pressupostos que lhe estão inerentes.

Perante o que foi mencionado, a reconceptualização do ensino, importante para o aumento da qualidade da aprendizagem dos alunos, passa mais por uma nova forma de pensar sobre este e acerca da sua interferência na aprendizagem e não tanto pelo uso de novos métodos de ensino (Entwistle, 1997). Não entusiasmar abordagens superficiais, aumentando um trabalho escolar que estimule abordagens profundas dos alunos à aprendizagem, surge, deste modo, como um dos primordiais desafios para todos os participantes do sistema educativo.

Em consonância com as conclusões das investigações relatadas, se os docentes desejam melhorar a qualidade da aprendizagem dos seus alunos, deveriam, em primeiro lugar, ter em perspectiva a situação de aprendizagem do ponto de vista dos alunos, o que requer, entre outros aspetos: (i) ter noção da sua maneira de conceituar a aprendizagem e o ensino, em relação às matérias ou à disciplina que leciona; (ii) estudar o contexto em que se está ensinando, na medida em que este influencia o modo como se aborda o ensino; (iii) procurar ser consciente e compreender a maneira como os seus 
alunos concebem a situação de ensino e aprendizagem em que se situam; e (iv) fazer uma revisão ao seu ensino, adequando-o e incrementando-o à evidência dessa consciência (Prosser \& Trigwell, 2000).

O ensino de qualidade não consiste, assim, na utilização de receitas milagrosas ou de modelos e técnicas infalíveis de ensino, na medida em que cada situação de ensino e aprendizagem é singular e irrepetível. O que se pretende é a compreensão de determinados princípios gerais para um ensino de qualidade, uma monitorização atenta da maneira como os alunos vivenciam a sua situação de aprendizagem e o conhecimento de determinadas soluções para situações urgentes (Prosser \& Trigwell, 2000).

Segundo Biggs e Tang (2011) um ensino de qualidade consiste num processo contínuo de observação das situações de ensino e aprendizagem, na perspectiva do aluno, adequando o seu ensino em consonância com os dados procedentes de uma continuada e aperfeiçoada monitorização. Um ensino de qualidade depende do contexto, pois o que resulta num certo contexto pode não resultar noutro. As estratégias de ensino e de aprendizagem que funcionam com alguns alunos podem não funcionar com outros. Inclui, também, a consciência da multiplicidade de alunos que fazem parte das turmas e tentativas de avaliar as suas percepções relativamente à situação de aprendizagem, com a finalidade de alterar, se for preciso, 0 contexto de ensino e aprendizagem, de modo a fomentar a opção por abordagens profundas. É imprescindível um trabalho permanente de autoavaliação, por parte do docente, para a prática de um ensino de qualidade. No entender de Ramsden (1992), pode não existir uma só solução para a questão da melhoria da qualidade do ensino.

De acordo com os dados das pesquisas neste âmbito (Koedinger, Booth \& Klahr, 2013; Schwartz \& Goldstone, 2016) poder-se-á dizer que, para fomentar um ensino de qualidade, é essencial que os docentes tenham conhecimento das suas próprias concepções de aprendizagem e de ensino, da sua maneira de abordar o ensino e dos respetivos resultados.

Na medida em que a abordagem focada no professor (abordagem transmissiva) parece desencorajar a adoção de uma abordagem profunda por parte dos alunos, pensamos ser útil que os professores se esforcem no sentido de refletirem sobre o modo como abordam o seu ensino (Lourenço \& Nogueira, 2014; Paiva 2007). A prática docente poderá estimular os alunos a desenvolverem abordagens à aprendizagem mais significativas, encaminhando a atenção dos mesmos mais para o entendimento dos conteúdos do que para a sua reprodução (Paiva \& Lourenço, 2015).

As abordagens ao ensino apresentam, também, uma natureza responsiva às exigências percebidas do contexto. Neste sentido, são também respostas dos docentes aos seus ambientes de ensino. Os 
diferentes modos como os docentes abordam o seu ensino estão relacionados com as distintas maneiras de entender o contexto de ensino (Rosário, Núñez, Ferrando, Paiva, Lourenço, Cerezo \& Valle, 2013).

Com frequência, nos diferentes níveis de ensino, os professores não entendem a razão pela qual, após terem dedicado algum tempo a ensinar determinado assunto utilizando distintos métodos de ensino, os alunos não o aprendem, alcançando, assim, classificações insuficientes nos vários momentos de avaliação. Questionam-se, igualmente, sobre os motivos pelos quais certas estratégias de ensino e de aprendizagem conseguem resultados positivos com uns alunos e não funcionam com outros, bem como têm muita dificuldade em aceitar que alguns alunos não manifestem certas competências essenciais (Saroyan \& Trigwell, 2015; Wang, Poscarella, Laird, \& Ribera, 2014).

Por outro lado, é observável, através da análise dos estudos empíricos sobre as abordagens à aprendizagem, que existe uma apreensão crescente em dois problemas comuns: os alunos, dos diferentes níveis de ensino, tendem a tornarem-se cada vez mais superficiais e menos profundos, relativamente às suas abordagens à aprendizagem (Entwistle \& Karagiannopoulou, 2013), e estão vivenciando grandes dificuldades em compreender textos informativos (Martínez \& Barrenetxea, 2002), mais especificamente nos que apresentam informação científica.

A investigação existente sugere que é elementar entender que, quando os alunos iniciam o estudo de determinada disciplina ou matéria, trazem consigo algumas experiências anteriores de aprendizagem. Assim sendo, tem-se que ajudar os alunos a compreender a relação entre essas experiências anteriores e conhecimentos prévios e os novos conhecimentos adquiridos. É, ainda, essencial esclarecer a finalidade que se pretende conseguir com o estudo de cada matéria. Fazer exercícios não é suficiente para que aprendam, têm que compreender o valor e a utilidade de cada assunto, ou seja, a sua instrumentalidade (Lourenço, 2007). É também importante explicitar os métodos de ensino e de avaliação do professor. Os alunos têm de entender o que é que o professor valoriza nos seus métodos de ensino e avaliação. Todos estes pormenores podem ter um papel importante na melhoria da qualidade do ensino e da aprendizagem.

\section{Considerações finais}

No início deste artigo foram colocadas algumas questões que todos os intervenientes no processo educativo gostariam de ver respondidas, a fim de incrementar o sucesso educativo. Assim, o desenvolvimento 
da reflexão centrou-se na análise das abordagens ao ensino dos professores, tentando incrementar a sua compreensão. Mais concretamente, este trabalho foi desenvolvido para aprofundar a compreensão da maneira como os professores abordam a sua forma de ensinar e, consequentemente, a sua influência nos resultados acadêmicos dos alunos.

Foi finalidade desta investigação estimular os professores a refletirem sobre as suas práticas docentes e sobre a maneira como fomentam a aprendizagem dos alunos no nível exigido.

Outro aspeto que pode condicionar o tipo de abordagem ao ensino é a falta de preparação dos professores para lidar com os conflitos em sala de aula, podendo contribuir significativamente para uma perspectiva redutora dos problemas dos alunos e, assim, desencadear posturas impositivas sem vislumbrar um caminho para a sua resolução (Lyra, Assis, Njaine, \& Pires, 2013).

É, também, importante conhecer as concepções dos alunos acerca da sua situação de aprendizagem e atuar de modo a desenvolver contextos de ensino e aprendizagem que os alunos vivenciem como motores de abordagens à aprendizagem profundas. Isto implica, necessariamente, a opção por uma abordagem centrada no aluno (Prosser \& Trigwell, 2000).

Relativamente a investigações futuras, a revisão da literatura PSI refere a importância de investigar em que medida as estratégias de ensino e as metodologias adotadas pelos docentes favorecem a eclosão da abordagem profunda, uma vez que seria desejável promovermos nos alunos uma atitude de exigência e de qualidade no estudo. Estes comportamentos investidos no trabalho acadêmico pressupõem níveis de autonomia e responsabilidade pessoais que devem ser trabalhados nas escolas. Outro aspeto a considerar seria realizar estudos de natureza qualitativa e/ou quantitativa que examinem as percepções dos alunos e dos professores acerca do ambiente de ensino e de aprendizagem, de modo a se construírem ambientes mais benéficos e impulsionadores de uma aprendizagem significativa. A percepção das contingências contextuais, ou seja, como é percebido o ambiente de aprendizagem, 0 tipo de competição, a tolerância ao erro, o grau de agressividade percebida e a qualidade da entreajuda entre os pares, contribuirão para avaliar em que medida a percepção de ambientes de aprendizagem mais ou menos fogosos e estimulantes, pode contribuir para a adoção de uma determinada abordagem, mais ou menos focada no aluno. É pertinente, ainda, o estudo da relação entre as abordagens ao ensino e variáveis relacionadas com o professor, nomeadamente os anos de experiência profissional, a organização da atividade letiva, tipo de trabalhos marcados aos alunos e seu feedback, trabalhos de casa e tutoria. 
Apesar de haver poucos estudos relativos ao construto Ambiente de Ensino (Lourenço \& Paiva, 2010b; Paiva \& Lourenço, 2010), as investigações revelam a importância do seu impacto na melhoria do processo de ensino e de aprendizagem. Se os professores possuírem os conhecimentos e as competências subjacentes a esta área, tal reverterá, seguramente, a favor da melhoria do rendimento escolar dos alunos. Para além deste conhecimento, será também relevante que os professores possam avaliar o tipo de ambiente escolar onde se movimentam para poderem intervir adequadamente e a tempo nas disfunções que possam surgir. É também essencial que percebam o impacto significativo de algumas variáveis no ambiente de ensino, bem como possuam competências que lhes permitam criar estratégias tendo sempre como principal objetivo a mestria dos alunos.

Por último, é consensual que não existe uma só forma correta de ensinar nem uma só forma correta de aprender. Contudo, apesar de haver algumas diretrizes para um ensino de qualidade, a prática da aprendizagem e do ensino tem que ser constantemente monitorizada e repensada. Para existir ensino e aprendizagem de qualidade tem de haver entusiasmo e consciência de que todos os intervenientes na ação educativa estão num caminho de descoberta permanente (Prosser \& Trigwell, 2000). Os docentes deveriam ter interesse em saber sempre mais acerca da multiplicidade dos seus alunos e incutir nos mesmos semelhante sentimento sobre os conteúdos estudados. Quando a comunidade educativa, sob a influência de fatores econômicos e socioculturais, for capaz de dominar e gerir um conjunto de fatores que se apresentam como os elementos essenciais de um ensino de elevada qualidade, o processo de mudança está iniciado e é irreversível.

\section{Referências}

Biggs, J. B. (1987). Student Approaches to Learning and Studying. Hawthorn: Australian Council for Educational Research.

Biggs, J. B. (1996). Western misperceptions of the Confucianheritage learning culture. In D. Watkins \& J. Biggs (Eds.), The Chinese Learner: cultural, psychological and contextual influences (pp. 45-67). Hong Kong: Cerc and Acer.

Biggs, J. B. (2001). The reflective institution: assuring and enhancing the quality of teaching and learning. Higher Education, 42, 221237.

Biggs, J. B. (2003). Teaching for quality learning at university (2. a ed.). Buckingham: Open University Press/Society for research into Higher Education. 
Biggs, J. B., \& Moore, P. J. (1993). The process of learning. Sydney: Prentice Hall of Australia.

Biggs, J., \& Tang, C. (2011). Teaching for quality learning at university (4a Ed.). England: McGraw-Hill.

Bruner, J. S. (1971). The functions of teaching. In W. Morse \& G. Wingo (Eds.), Classroom Psychology (pp. 57-72). Glenview: Scott Foresman.

Chaleta, M. E. R. (2002). Abordagens ao Estudo e Estratégias de Aprendizagem no Ensino Superior (Tese de Doutoramento não publicada). Retirado de http://roar.eprints.org/1088/

Duarte, A. (2002). Aprendizagem, ensino e aconselhamento educacional - uma perspectiva cognitivo-motivacional. Porto: Porto Editora.

Duarte, A. (2004). Auto-regulação e abordagens à aprendizagem. In A. Lopes da Silva, A. M. Duarte, I. Sá, \& A. M. Veiga Simão (Eds.), Aprendizagem Auto-Regulada pelo Estudante (pp. 4353). Porto: Porto Editora.

Entwistle, N. J. (1997). Contrasting Perspectives on Learning. In F. Marton, D. Hounsell, \& N. Entwistle (Eds.), The Experience of Learning (pp. 3-22). Edinburgh: Scottish Academic Press Limited.

Entwistle, N., \& Karagiannopoulou, E. (2013). Influences on personal understanding: Intentions, approaches to learning, perceptions of assessment, and a 'meeting of minds'. Psychology Teaching Review, 19(2), 80-96.

Entwistle, N. J., \& Ramsden, P. (1983). Understanding student learning. London: Croom-Helm.

Entwistle, N. J., Kozéki, B., \& Tait, H. (1989). Pupils' Perceptions of School and Teachers II-Relationships with Motivation and Approaches to Learning. British Journal of Educational Psychology, 59, 340-350.

Ginns, P., Martin, A. J., \& Papworth, B. (2014). Student Learning Theory goes (back) to (high) school. Instructional Science, 42(4), 485-504.

Grácio, M. L. F. (2002). Concepções do Aprender em Estudantes de Diferentes Graus de Ensino. Do final da Escolaridade Obrigatória ao Ensino Superior. Uma perspectiva fenomenográfica (Tese de doutoramento não publicada). Retirado de http: // roar.eprints.org/1088

Kember, D. (2000). Action Learning and Action Research - improving the quality of teaching and learning. London: Kogan.

Kember, D., Biggs, J., \& Leung, D. Y. P. (2004). Examining the multidimensionality of approaches to learning through the development of a revised version of the Learning Process Questionnaire. British Journal of Educational Psychology, 74, 261-280. 
Kember, D., \& Kwan, K. (2000). Lecturers' approaches to teaching and their relationship to conceptions of good teaching. Instructional Science, 28, 469-490.

Koedinger, K, Booth, J, \& Klahr, D. (2013). Instructional complexity and the science to instrain it. Science, 342(61), 935-937.

Lourenço, A. A. (2007). Processos auto-regulatórios em alunos do 3.o Ciclo do Ensino Básico: contributos da auto-eficácia e da instrumentalidade. (Tese de doutoramento). Retirado de http://repositorium.sdum.uminho.pt

Lourenço, A. A., \& Nogueira, C. M. L. (2014). Percepções sobre as abordagens à aprendizagem: estudo de variáveis psicológicas. Educação e Filosofia, 28(55), 323-372.

Lourenço, A. A., \& Paiva, M. O. A. (2010a). A motivação escolar e o processo de aprendizagem. Ciências \& Cognição, 15(2), 132141.

Lourenço, A. A., \& Paiva, M. O. A. (2010b). A percepção do clima de escola pelos alunos da ESAH. In L. S. Almeida, B. D. Silva, \& S. Caires (Orgs.), Actas do I Seminário Internacional "Contributos da Psicologia em Contextos Educativos" (pp. 1501-1516), Braga: Universidade do Minho.

Lyra, G. F. D., Assis, S. G., Njaine, K., \& Pires, T. O. (2013). Sofrimento psíquico e trabalho docente - implicações na detecção de problemas de comportamento em alunos. Estudos e Pesquisas em Psicologia, 13(2), 724-744.

Martin, E., Prosser, M., Trigwell, K., Ramsden, P., \& Benjamin, J. (2000). What university teachers teach and how they teach it. Instructional Science, 28, 387-412.

Martínez, M. A. E., \& Barrenetxea, I. G. (2002). Dificultades de comprensión lectora en estudiantes universitarios. Implicaciones en el diseño de programas de intervención. Revista de Psicodidáctica, 10, 59-74.

Marton, F. (1988). Describing and Improving Learning. In R. Schmeck (Ed.), Learning strategies and learning styles (pp. 53-82). New York: Plenum Press.

Marton, F., \& Säljö, R. (1976). On qualitative differences in learning: I - Outcome and Process. British Journal of Educational Psychology, 46, 4-11.

Marton, F., \& Säljö, R. (1997). Approaches to learning. In F. Marton, D. Hounsell, \& N. Entwistle (Eds.), The Experience of Learning (pp. 39-58). Edinburgh: Scottish Academic Press Limited.

Paiva, M. O. A. (2007). Abordagens à aprendizagem e abordagens ao ensino: Uma aproximação à dinâmica do aprender no Secundário. (Tese de doutoramento não publicada). Retirado de http://repositorium.sdum.uminho.pt

Paiva, M. O. A., \& Lourenço, A. A. (2010). A percepção do ambiente de ensino pelos professores da ESAH. In L. S. Almeida, B. D. 
Silva \& S. Caires (Orgs.), Actas do I Seminário Internacional "Contributos da Psicologia em Contextos Educativos" (pp. 14851500), Braga: Universidade do Minho.

Paiva, M. O. A., \& Lourenço, A. A. (2015) Abordagens à aprendizagem: a dinâmica para o sucesso académico, Revista CES Psicologia, 8(2), 7-75.

Prosser, M., \& Trigwell, K. (1997). Relations between perceptions of the teaching environment and approaches to teaching. British J ournal of Educational Psychology, 67, 25-35.

Prosser, M., \& Trigwell, K. (1998). Teaching for learning in higher education. Buckingham: Open University Press.

Prosser, M., \& Trigwell, K. (2000). Understanding Learning and Teaching - The Experience in Higher Education. Buckingham: Open University Press.

Prosser, M., \& Trigwell, K. (2006). Confirmatory factor analysis of the approaches to teaching inventory. British J ournal of Educational Psychology, 76, 405-419.

Prosser, M., Trigwell, K., \& Taylor, P. (1994). A phenomenographic study of academics' conceptions of science learning and teaching. Learning and Instruction, 4, 217-231.

Ramsden, P. (1992). Learning to Teach in Higher Education. London: Routledge.

Ramsden, P. (1997). The context of learning in academic departments. In F. Marton, D. Hounsell, \& N. Entwistle (Eds.), The Experience of Learning (pp. 198-216). Edinburgh: Scottish Academic Press Limited.

Ramsden, P., \& Entwistle, N. J. (1981). Effects of academic departments on students' approaches to studying. British J ournal of Educational Psychology, 51, 368-383.

Richardson, J. T. E. (2000). Researching Student Learning Approaches to Studying in Campus-based and Distance Education. The society for research into Higher Education. Buckingham: Open University Press.

Rosário, P. (1999). As abordagens dos alunos ao estudo: diferentes modelos e suas inter-relações. Psicologia: Teoria, Investigação e Prática, 4(1), 43-61.

Rosário, P. (2004). Estudar o estudar: (Des)venturas do Testas. Porto: Porto Editora.

Rosário, P. (2005). Motivação e aprendizagem: uma rota de leitura. In M. C. Taveira (Coord.). Temas de Psicologia Escolar. Contributos de um projecto científico-pedagógico (pp. 23-60). Coimbra: Quarteto Editora.

Rosário, P., Almeida, L., Núñez, J. C., \& González-Pienda, J. A. (2004). Abordagem dos alunos à aprendizagem: análise do construto. Psico-USF, 9(2), 117-127. 
Rosário, P., Ferreira, I., \& Cunha, A. (2003). Inventário de Processos de Estudo (IPE). In M. Gonçalves, M. Simões, L. Almeida \& C. Machado (Coords.), Avaliação psicológica - instrumentos validados para a população portuguesa (pp. 145-164). Coimbra: Quarteto Editora.

Rosário, P., Ferreira, I., \& Guimarães, C. (2001). Abordagens ao estudo em alunos de alto rendimento. Sobredotação, 2(2), 121137.

Rosário, P., González-Pienda, J. A., Cerezo, R., Pinto, R., Ferreira, P., Lourenço, A., \& Paiva, O. (2010). Eficacia del programa "(Des)venturas de Testas" para la promoción de un enfoque profundo de estudio. Psicothema, 24(4), 828-834.

Rosário, P., Núñez, J. P., Ferrando, P. J., Paiva, M. O. A., Lourenço, A. A., Cerezo, R., \& Valle, A. (2013). The relationship between approaches to teaching and approaches to studying: A twolevel structural equation model for biology achievement in high school. Metacognition and Learning, 8, 47-77.

Rosário, P., Núñez, J. C., González-Pienda, J. A., Almeida, L., Soares, S., \& Rúbio, M. (2005). El aprendizaje escolar examinado desde la perspectiva del «Modelo 3P» de J. Biggs. Psicothema, 17(1), 20-30.

Saroyan, A., \& Trigwell, K. (2015). Higher education teachers' professional learning: Process and outcome. Studies in Educational Evaluation, 46, 92-101.

Schwartz, D., \& Goldstone, R. (2016). Learning as coordination: cognitive psychology and education. In L. Corno \& E. Anderman (Eds.), Handbook of Educational Psychology (pp. 61-75). New York: Routledge.

Sheppard, C., \& Gilbert, J. (1991). Course design, teaching method and student epistemology. Higher Education, 22(3), 229-249.

Tobin, K. (1987). The role of wait time. Review of Educational Research, 57, 69-95.

Trigwell, K., \& Prosser, M. (1996). Congruence between intention and strategy in university science teachers' approaches to teaching. Higher Education, 32(1), 77-87.

Trigwell, K., \& Prosser, M. (2004). Development and use of the approaches to teaching inventory. Educational Psychology Review, 16(4), 409-424.

Trigwell, K., Prosser, M., \& Taylor, P. (1994). Qualitative differences in approaches to teaching first year university science. Higher Education, 27, 75-84.

Trigwell, K., Prosser, M., \& Waterhouse, F. (1999). Relations between teachers' approaches to teaching and students' approaches to learning. Higher Education, 37, 57-70.

Tsai, P-S, Tsai, C-C, \& Hwang, G-H. (2015). The effects of instructional methods on students' learning outcomes requiring 
different cognitive abilities: context-aware ubiquitous learning versus traditional instruction. Interactive Learning Environments, 23(3), doi:10.1080/10494820.2015.1035730.

Vasconcelos, C., Praia, J. F., \& Almeida, L. S. (2003). Teorias de aprendizagem e o ensino/aprendizagem das ciências: da instrução à aprendizagem, Psicologia Escolar e Educacional, 7(1), 11-19.

Wang, J-S, Pascarella, E. T., Laird, T. F. N, \& Ribera, A. K. (2014). Studies in Higher Education, 39(7). doi: 10.1080/03075079.2014.914911.

\section{Endereço para correspondência Maria Olímpia Almeida de Paiva}

Centro de Investigação em Psicologia e Educação do AEAH - CIPE

Agrupamento de Escolas Alexandre Herculano

Avenida Camilo, 4300-096, Porto, Portugal

Endereço eletrônico: olimpiapaiva0212@gmail.com

\section{Abílio Afonso Lourenço}

Centro de Investigação em Psicologia e Educação do AEAH - CIPE

Agrupamento de Escolas Alexandre Herculano

Avenida Camilo, CEP 4300-096, Porto, Portugal

Endereço eletrônico: privadoxy@gmail.com

Recebido em: 12/01/2014

Reformulado em: 04/04/2017

Aceito em: 03/05/2017

\section{Notas}

* Doutoramento em Ciências da Educação pela Universidade do Minho, Braga e Pós-doutoramento em Psicologia da Educação pela Universidade Fernando Pessoa, Porto, Portugal. Possui 40 artigos científicos em revistas nacionais e internacionais, 1 livro, 5 capítulos de livro e com um h-index de 9.

** Doutoramento em Ciências da Educação pela Universidade do Minho, Braga e Pós-doutoramento em Psicologia da Educação pela Universidade Fernando Pessoa, Porto, Portugal. Possui 40 artigos científicos em revistas nacionais e internacionais, 1 livro, 6 capítulos de livro e com um h-index de 9.

Este artigo de revista Estudos e Pesquisas em Psicologia é licenciado sob uma Licença Creative Commons Atribuição-Não Comercial 3.0 Não Adaptada. 